\title{
La reivindicación \\ de competencias \\ de Colombia Compra \\ Eficiente por el \\ Consejo de Estado: \\ ¿nuevo alcance de la \\ potestad reglamentaria \\ o interpretación \\ extensiva de la ley por \\ la jurisprudencia?
}

Mónica Sofía Safar Díaz

1 Magister in Artis en Derecho, Economía y Políticas Públicas del Instituto Universitario de Investigación José Ortega y Gasset y la Universidad Complutense de Madrid, Madrid, España. Máster universitario en Análisis Económico del Derecho y candidata a doctora en Derecho de la Universidad Complutense de Madrid, Madrid, España. Docente investigadora de los departamentos de Derecho Administrativo y Derecho Económico de la Universidad Externado de Colombia, Bogotá, Colombia. Asesora y consultora de empresas públicas y privadas en materia de contratación estatal. Correo electrónico: monica.safar@uexternado.edu.co. Fecha de recepción: 20 de septiembre de 2017. Fecha de modificación: 20 de octubre de 2017. Fecha de aceptación: 30 de octubre de 2017. Para citar el artículo: SAFAR DíAZ, MÓnICA. "La reivindicación de competencias de Colombia Compra Eficiente por el Consejo de Estado: ¿nuevo alcance de la potestad reglamentaria o interpretación extensiva de la ley por la jurisprudencia?", Revista digital de Derecho Administrativo, Universidad Externado de Colombia, n. ${ }^{\circ} 19,2018$, pp. 159-179. DOI: https://doi.org/10.18601/21452946.n19.08 


\title{
RESUMEN
}

La discusión sobre la naturaleza jurídica de los documentos expedidos por la Agencia Nacional de Contratación no es un asunto del todo tranquilo en la academia y la doctrina, pero con ocasión de un reciente pronunciamiento del Consejo de Estado sobre las competencias de Colombia Compra Eficiente es importante dimensionar el alcance de los mismos a partir del estudio de la naturaleza jurídica de la entidad, la órbita de la potestad reglamentaria en la atribución de funciones a dicha entidad y el impacto que ello puede tener en el concepto de la descentralización territorial.

Palabras clave: Agencia Nacional de Contratación, Potestad reglamentaria, Competencias administrativas, Fijación de políticas públicas, Descentralización territorial, Consejo de Estado.

\section{The recognition of Competences \\ to Colombia's Public Procurement Agency by the State Council: A New Outreach of Agency Regulatory Powers or an Extensive Interpretation of the Law in the Administrative Jurisprudence?}

\begin{abstract}
The debate around the legal nature of administrative acts issued by Colombia's Public Procurement Agency is not a tranquil matter amid scholars in administrative law. With a recent decision of the State Council, regarding the administrative competences of the National Agency in charge of Public Procurement policymaking, this paper aims to determine the scope of its regulatory powers by examining its legal nature, the reach of its rulemaking authority and the impact assessment of rules over the territorial decentralization.
\end{abstract}

Keywords: Public Procurement Agency, Rulemaking Authority, Regulatory Powers, Policymaking, Territorial Decentralization, Colombian State Council. 


\section{INTRODUCCIÓN}

En el marco de la novedad que representa en nuestro ordenamiento jurídico y estructura administrativa la existencia de una entidad específicamente dedicada a temas propios de la contratación pública, vale la pena analizar la posición que la jurisprudencia tiene al respecto dentro del concepto más tradicional del derecho administrativo, esto es, la legalidad, y su manifestación en la concepción misma de la Administración pública.

Este asunto, que no es pacífico en la doctrina ${ }^{2}$, adquiere nuevamente protagonismo a partir de un reciente fallo proferido por la Sección Tercera del Consejo de Estado, con ocasión de la demanda de nulidad presentada contra la previsión contemplada en el reglamento del Estatuto General de Contratación de la Administración Pública sobre la atribución a la Agencia Nacional de Contratación de la competencia para determinar la forma y estructuración de los acuerdos marco de precios, figura expresamente consagrada como procedimiento de escogencia de contratistas dentro de la modalidad de selección abreviada, al tenor del literal a del numeral segundo del artículo 2 de la Ley 1150 de 2007 y en el parágrafo quinto de la misma norma, manifestando al respecto que las competencias conferidas a esta entidad estatal en su norma de creación, la cual tiene rango normativo de ley, justifican y habilitan la atribución funcional efectuada por el reglamento.

Así, con independencia de la posición que se tome sobre lo dicho por la máxima instancia del contencioso administrativo, vale la pena hacer una reflexión sobre el contenido y alcance de las competencias de la Agencia Nacional de Contratación y la delgada línea que existe entre la atribución funcional a este organismo y el alcance de la potestad reglamentaria, y el papel que la jurisprudencia está jugando en la delimitación de ambos conceptos, para lo cual: i) empezaremos por analizar la naturaleza jurídica de la Agencia Nacional de Contratación, ii) seguiremos con el estudio del alcance de la potestad reglamentaria sobre esta entidad ${ }_{i}$ y iii) por último, analizaremos el impacto de lo dicho por la jurisprudencia sobre el concepto de descentralización territorial, para presentar algunas conclusiones y apreciaciones al respecto.

\section{PREMISA DE ANÁLISIS: ¿QUUÉ ES JURÍDICAMENTE LA AGENCIA NACIONAL DE CONTRATACIÓN?}

Un gobierno eficaz debe generar herramientas e instituciones que proyecten parámetros de calidad en la ejecución de las políticas públicas que traza el

2 Cfr. Héctor Santaella, "El doble nivel, vinculante y no vinculante, de la reglamentación en la contratación pública en Colombia", en Contratos Públicos: problemas, perspectivas y prospectivas, XVIII Jornadas internacionales de Derecho Administrativo, Bogotá, Universidad Externado de Colombia, 2017, pp. 783 y ss. 
Estado $^{3}$, y en esta medida debe efectuarse una planificación que permita esbozar los objetivos que se proyectan a un corto, mediano y largo plazo por parte de la Administración, lo que implica de suyo idear la estructura organizacional idónea para el desarrollo de la misma; y ello cobija igualmente a la contratación pública, por su importancia como herramienta transversal a todo el Estado, de modo que se hace necesario buscar herramientas que contrarresten el marco subjetivo que sobresale en este ámbito, lo que ha llevado, a juicio del gobierno de turno, a suplir la necesidad de contar con un ente especializado en la política pública de la contratación estatal ${ }^{4}$, justificada como una medida de regulación y supervisión que permita centralizar y optimizar los lineamientos de la contratación pública ${ }^{5}$.

3 " [L]a instrumentalización legal, deberá adaptarse a la tradición política e institucional de cada país, según sus peculiaridades, que habrá que tomar en consideración. Allí donde el poder judicial tenga una notable tradición, resultan ideales los instrumentos contractuales para vincular al Gobierno; allí donde la separación de poderes sea verdadera y firme, la consolidación de la regulación en un instrumento de rango legal servirá de garantía a los inversores contra posibles veleidades del Ejecutivo; allí donde no haya una administración ilustrada, capaz, bien dotada, será necesario promover con toda rapidez una Administración reguladora de nuevo cuño, capaz de hacer frente a los problemas. En todo caso, la regulación para la competencia requiere equiparamiento institucional (institutional endowmwnt), objetivos claros y decisión. En buena medida consiste en crear un marco de actuación -de derecho y deberes- que hagan posible el nacimiento de un mercado que al principio no se sostiene por sí mismo; y, en segundo lugar, unas instituciones de nuevo cuño llamadas a aplicarlo en cada uno de los sectores, supervisando de un modo continuo la competencia y adoptando las medida necesarias para su defensa". GASPAR ArIÑO OrTIZ, Lecciones de administración (y políticas públicas), 1. a ed., Madrid: Iustel, 2011, p. 854.

"La baja cultura de la legalidad es incompatible con la eficacia y eficiencia de la Administración, tanto por razones de falta de profesionalismo entre los seleccionados con criterios fraudulentos, como por falta de honestidad en el ejercicio de su cargo, pues todos los incentivos existen para que la Administración sea tomada como botín y se patrimonialicen partidista y personalmente los fondos públicos. En países con baja cultura de la legalidad la aplicación imparcial de la norma es una quimera". Manuel Villoria Mendieta, Ética pública y buen gobierno. Regenerando la democracia y luchando contra la corrupción desde el servicio público, Madrid: Instituto Nacional de Administración Pública, 2015, p. 59.

5 " $[\mathrm{L}] \mathrm{a}$ ausencia de una instancia rectora se configura como el principal obstáculo para una mejor gestión contractual, tema que en los países a la vanguardia en materia fiscal tiene un lugar privilegiado, por el efecto que las actuaciones de las entidades en esa materia tienen en términos de eficiencia y eficacia en la ejecución del gasto del Estado. La necesidad de reforzar el aspecto institucional se justifica no solo por las funciones específicas que cumpliría dicha instancia para la solución de muchas de las deficiencias específicas de la gestión contractual, sino también para la articulación de la política presupuestal y contractual y la generación de mayor capacidad en las entidades para su desarrollo. Las funciones de la institucionalidad estarán relacionadas con el diseño de políticas y estrategias de contratación, la proposición de la agenda normativa de la Administración en materia de contratación, la definición de los estándares de los procesos de contratación, información consolidada sobre precios, proveedores y estructuras de los mercados en los que adelanta sus adquisiciones; criterios teóricos y prácticos definidos que permitan la aplicación de esquemas de selección de proveedores y formas contractuales alineadas 
En atención a lo anterior, actualmente la competencia general de lineamientos en materia de contratación estatal, que comprende aspectos de medición del desempeño y análisis de la funcionalidad de las estrategias que se implementan en las relaciones contractuales del Estado, se ha atribuido en nuestro medio a una entidad específicamente diseñada para el efecto, cual es la Agencia Nacional de Contratación, Colombia Compra Eficiente, creada mediante el Decreto Ley 4170 de 2011, en el marco de las facultades extraordinarias conferidas por el Congreso de la República al Gobierno Nacional mediante la Ley 1444 de 2011, como un "ente rector de la contratación pública para desarrollar e impulsar políticas públicas y herramientas orientadas a asegurar que el sistema de compras y contratación pública obtenga resultados óptimos en términos de la valoración del dinero público a través de un proceso transparente"

En efecto, dado que no existía voluntad alguna de hacer una reforma constitucional para crear organismos autónomos a solicitud del Gobierno Nacional, y siendo una iniciativa propia de este la necesidad de hacer una reestructuración de la Administración pública del orden nacional, se optó para el caso de la Agencia Nacional de Contratación por la figura de unidad administrativa especial con personería jurídica en los términos de los artículos 67 y 82 de la Ley 489 de 1998, como organismo creado por la ley (o decreto con fuerza de ley) con la autonomía administrativa y patrimonial y que cumple funciones administrativas para desarrollar o ejecutar programas propios de un ministerio o departamento administrativo (en este caso, del Departamento Nacional de Planeación) con el objetivo de "desarrollar e impulsar políticas públicas y herramientas orientadas a la organización y articulación de los partícipes en los procesos de compras y contratación pública con el fin de lograr una mayor

con las características de las diferentes transacciones; el desarrollo de mecanismos que faciliten la cooperación y concurrencia de distintas entidades en compras comunes y la representación del Gobierno en las distintas instancias internacionales relacionadas con la toma de decisiones, incluidos los acuerdos de integración económica". Colombia, DEpartamento Nacional de Planeación, Bases del Plan Nacional de Desarrollo 2010-2014, p. 486.

6 De acuerdo con las consideraciones expuestas en el Decreto Ley 4170 de 2011, norma de creación de Colombia Compra Eficiente, "es una necesidad de país generar una política clara y unificada en materia de compras y contratación pública, con lineamientos que sirvan de guía a los administradores públicos en la gestión y ejecución de recursos, que permita que su quehacer institucional pueda ser medido, monitoreado y evaluado y genere mayor transparencia en las compras y la contratación pública" y "conscientes de esa necesidad en las Bases del Plan Nacional de Desarrollo 2010-2014, 'Prosperidad para Todos', se reconoció la necesidad de tener una institucionalidad rectora en gestión contractual pública que promueva, articule, implemente, haga el seguimiento necesario a las políticas que orienten la actividad estatal, proporcione instrumentos gerenciales en dicha actividad y por esa vía colabore activamente en la mitigación de riesgo de corrupción en la inversión de los recursos públicos". 
eficiencia, transparencia y optimización de los recursos del Estado"7. De ahí que dentro de los fundamentos que erigieron la confección de dicha institución se tuviese como eje central la búsqueda de una política clara y unificada en materia de compras y contratación pública, a cargo de una organización especializada que dirigiera los lineamientos y directrices bajo los cuales las entidades públicas guiarían la gestión fiscal.

Es así como queda claro que Colombia se ha unido a la tendencia que concibe la necesidad de contar con un organismo técnico y especializado en materia de contratación pública, y ha optado porque el mismo se encuentre dentro de la rama ejecutiva del poder público como parte integrante de la Administración pública, lo que implica un esquema en el cual su actuación se encuentra delimitada por la principal función de esta parte del Estado, cual es, de manera primigenia, la de cumplir la ley, lo que se deriva en su función

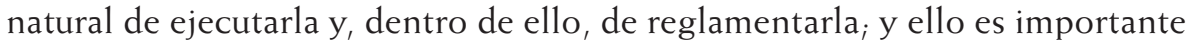
para efectos de la comprensión del alcance de las competencias conferidas a esta entidad, pues, de contar con otra naturaleza y estar ubicada en otra parte de la estructura misma del Estado, sus funciones y la naturaleza de sus actos serían diferentes ${ }^{8}$.

\section{$7 \quad$ Artículo 2. ${ }^{\circ}$, Decreto Ley 4170 de 2011.}

8 "De manera concreta, esta normatividad diversa y de influencia variada internacional, se manifiesta en instituciones contractuales, como el establecimiento de un sistema de contratación pública que estructura y jerarquiza las entidades públicas vinculadas con la actividad contractual. Los textos legales definen, de manera uniforme, que los sistemas de contratación se estructuran bajo un mismo esquema jerarquizado desde el orden nacional (o federal), al interior de la Rama Ejecutiva, con el Ministerio de Hacienda (de Economía y Finanzas), como institución tutora del Gobierno Central, o las entidades de planeación (Colombia y Venezuela), y un Órgano Rector, descentralizado, a quien se confía la Coordinación del Sistema y la preparación de políticas públicas de contratación. El funcionamiento de este Órgano Rector podrá generar cierta incertidumbre en varios países, por sus funciones normativas (reglamentarias), que pueden adaptarse mal a su condición de organismo descentralizado por servicios. Más cercanos a las agencias gubernamentales americanas, con funciones regulatorias y sancionatorias, los Órganos Rectores de contratación responden al concepto de establecimiento público descentralizado de carácter técnico, propio de la organización administrativa de influencia francesa. Tal vez por ello, aunque algunas legislaciones les confían directamente el diseño y elaboración de normas generales (Nicaragua), otras, mas prudentes frente a la tradición administrativista, les otorgan competencias limitadas consistentes en proponer políticas, proyectar normas legales y reglamentarias (Argentina), o asesorar en la elaboración y seguimiento de las políticas (Uruguay), lo que sugiere un alcance restringido de sus competencias, al prever funciones operativas de desarrollo e impulsión de las políticas públicas contractuales (Colombia), la promoción de la máxima competencia posible en la contratación (Chile), o dictar actos administrativos que garanticen la aplicación de la ley y sus reglamentos (Panamá). La limitación de las posibilidades de reglamentación por organismos técnicos explicaría por qué algunas pocas legislaciones establecen en el Ministerio de Economía y Finanzas la calidad de órgano rector (Bolivia, El Salvador). En estos casos, el gobierno ejerce así directamente la tradicional competencia reglamentaria". JosÉ LuIS BENAVIDES, "Tendencias 
Así las cosas, Colombia Compra Eficiente hace parte del sector administrativo de planeación, al estar adscrita a su cabeza, el Departamento Nacional de Planeación" ${ }^{9}$ con funciones específicas de "proponer al Gobierno Nacional las políticas públicas, planes, programas y normas en materia de compras y contratación pública buscando la efectividad entre la oferta y la demanda en el mercado y criterios de racionalización normativa, con el fin de lograr una mayor eficiencia, transparencia y optimización de los recursos del Estado", "Desarrollar, implementar y difundir las políticas públicas, planes, programas, normas, instrumentos y herramientas que faciliten las compras y contratación pública del Estado y promuevan las mejores prácticas, la eficiencia, transparencia y competitividad del mismo, a fin de que se cumplan los principios y procesos generales que deben gobernar la actividad contractual de las entidades públicas", "Difundir las normas, reglas, procedimientos, medios tecnológicos y mejores prácticas para las compras y la contratación pública, y promover y adelantar con el apoyo y coordinación de otras entidades públicas cuyo objeto se los permita, la capacitación que considere necesaria, a fin de orientar a los partícipes en el proceso contractual" y "Brindar apoyo a las entidades territoriales para la adecuada aplicación de las políticas, instrumentos y herramientas en materia de compras y contratación pública", entre otras. Lo anterior se reafirma con el hecho de que, al tenor del artículo 1.2.1.1 del Decreto 1082 de 2015, reglamentario de Sector Administrativo de Planeación Nacional, expresamente se consagra que Colombia Compra Eficiente es una entidad adscrita a la cabeza del mismo.

Queda claro, entonces, que desde el enfoque normativo las competencias de la Agencia Nacional de Contratación, que corresponden a las funciones expresamente atribuidas, de carácter irrenunciable e improrrogable, no negociables, de estricto cumplimiento y excepcionalmente delegables, se encuentran plenamente identificadas en una norma que tiene claro rango de ley, cumpliéndose con ello el mandato claro el artículo 121 constitucional de que ninguna autoridad del Estado podrá ejercer funciones distintas de las que le atribuyen la Constitución y la ley, que junto con el $6^{\circ}$ de la misma Carta completan el principio de legalidad, al establecerse que los funcionarios públicos son responsables por la infracción de la Constitución y la ley, y por omisión o extralimitación de sus funciones; y tales funciones corresponden estrictamente a la estructuración de políticas públicas relativas al tema de la contratación estatal para ser propuestas al Gobierno Nacional -a través de su cabeza, el Departamento Nacional de Planeación-y aplicar las mismas, una

generales de la contratación pública en América Latina", en La contratación pública en América Latina, Bogotá: Universidad Externado de Colombia, 2016, pp. 49 y 50.

9 Artículo 42 Ley 489 de 1998: "El Sector Administrativo está integrado por el Ministerio o Departamento Administrativo, las superintendencias y demás entidades que la ley defina como adscritas o vinculadas a aquellos según correspondiere a cada área". 
vez aprobadas por este e implementadas a través de los instrumentos jurídicos correspondientes (actos administrativos de carácter general), junto con los demás programas y normas existentes al respecto y de rango normativo, a través de diferentes herramientas idóneas para el efecto, lo que se acompasa con la función de hacer difusión de dichas políticas ya aprobadas jurídicamente y ser un apoyo al nivel territorial, descentralizado por mandato constitucional, para su materialización.

En este orden de ideas, se observa que el papel de Colombia Compra Eficiente se enmarca dentro de la jerarquía normativa clásica y que ha sido fundamental para la comprensión y aplicación del derecho administrativo en nuestro medio, pues como entidad técnica especializada que cumple funciones que le corresponderían al Departamento Nacional de Planeación, se encarga de estudiar la materia de la contratación pública para informar de la misma a la cabeza de su sector (upstream), así como generar instrumentos de materialización de lo expresamente dispuesto en la normas que se encuentren dentro del ordenamiento jurídico, y expresamente dentro del marco que el mismo establece (downstream $)^{10}$; la pregunta que surge, entonces, es si en el marco de esta estructura claramente definida puede inferirse, a partir de las manifestaciones de la jurisprudencia, si esta última función comprende componentes de naturaleza regulatoria y, por ende, de obligatorio cumplimiento, especialmente frente al nivel territorial.

\section{2. ¿HASTA DÓNDE EL ALCANCE DE LA POTESTAD REGLAMENTARIA COBIJA NORMATIVAMENTE A COLOMBIA COMPRA EFICIENTE?}

Ahora bien, no obstante lo anterior, la interpretación de las disposiciones normativas que dieron nacimiento a la Agencia Nacional de Contratación y las normas posteriores que la han desarrollado denota que la presencia de la función legislativa se ha visto opacada, toda vez que ha sido la potestad reglamentaria que ostenta el presidente, por el mandato constitucional consagrado en el numeral 11 del artículo 189, la que ha tomado un papel protagónico respecto del marco normativo en el que se desenvuelve dicha institución, situación que debe ponerse de presente teniendo en cuenta que "en principio la Administración tan solo tiene un rol de ejecución de la ley debido a su condición de instrumentos de aplicación de la voluntad general expresada integran la teoría jurídica general de la organización administrativa. Ellos son: jerarquía, competencia, centralización y descentralización". MirIAM IVANEGA, Instituciones de derecho administrativo, $2^{a}$ ed., Bogotá: Universidad Externado de Colombia, 2013, p. 261. 
por el legislador"11, y la potestad reglamentaria se concibe como una facultad constitucional estrictamente complementaria de la ley ${ }^{12}$.

$\mathrm{Al}$ respecto, el Consejo de Estado se ha pronunciado indicando que

En este orden de ideas, la regla general en materia reglamentaria la tiene el Presidente de la República por dos vías: por una parte, a través de la reglamentación directa de la ley cuando sea indispensable para hacer posible su cumplimiento (Constitución, artículo 189.11), pues en su condición de Suprema Autoridad Administrativa le corresponde "ejercer la potestad reglamentaria mediante la expedición de los decretos, resoluciones y órdenes necesarias para la cumplida ejecución de las leyes"; y por otra parte, en los casos en que la Constitución le permite desarrollar directamente sus preceptos normativos, caso en el cual la potestad normativa o reglamentaria es directamente de la Constitución, asunto que en algunas oportunidades la jurisprudencia de esta Corporación denominó como deslegalización de materias en favor de la administración, y que, mirado desde otro punto de vista, no es más que el reconocimiento constitucional de la potestad reglamentaria en cabeza del Presidente, no ya a nivel de la ley, sino del acto administrativo de carácter general, pues orgánica y funcionalmente el acto sería administrativo y no legislativo, excepto que el constituyente le hubiera establecido efectos legislativos, como en el caso del artículo 341 inciso $3 .^{\circ}$ constitucional ${ }^{13}$.

Es así como, la potestad reglamentaria -con independencia de la regla excepcional de la facultad a que se refiere el artículo 150 constitucional de autorizar al presidente de la República a expedir normas con fuerza de ley bajo escenarios de delegación denominados decretos ley ${ }^{14}$ - corresponde a la función que

11 José Luis BenAVIDES, El contrato estatal, entre el derecho público y el derecho privado, 2. a ed., Bogotá: Universidad Externado de Colombia, 2004, p. 118.

12 "La facultad reglamentaria, que la Constitución le reconoce al poder ejecutivo, es una facultad gobernada por el principio de necesidad, que se materializa justamente en la necesidad que en un momento dado existe de detallar el cumplimiento de una ley que se limitó a definir de forma general y abstracta determinada situación jurídica". Consejo de Estado, Sala de Consulta y Servicio Civil, Concepto del 16 de abril de 2015, Rad. 2223. En el mismo sentido, ver Consejo de Estado, Sala de lo Contencioso Administrativo, Sección Tercera, Sentencia del 3 de diciembre de 2007, Exp. 24715.

13 Consejo de Estado, Sala de lo Contencioso Administrativo, Sección Tercera, Auto del 19 de febrero de 1998, Exp. 14092.

14 "En cuanto a su finalidad, los decretos reglamentarios están en el umbral de la ejecución de la ley y por tal circunstancia dan comienzo a la función administrativa. Ellos no se expiden en un ejercicio teórico-jurídico de los gobiernos. Es por la necesidad de definir la orientación de la ley y de señalar pautas para su aplicación a los numerosos funcionarios administrativo [...] es motivo de discusión el alcance del decreto reglamentario. No se trata de repetir la ley, porque sería inoficioso. Tampoco de adicionarla o llevarla a donde ella no quiso o, a materias que son de reserva legal, materia regulable por el Congreso como legislador. Se trata más bien de proyectar su espíritu en las normas reglamentarias para que cubra todo el espectro que la ley no expreso en palabras pero que fluye de la voluntad del legislador, en esa y en otras leyes convergentes". Jaime Perdomo Vidal, Derecho 
le asiste a la Suprema Autoridad Administrativa de ejecutar la ley mediante la expedición de los decretos, resoluciones y órdenes necesarios ${ }^{15}$, de manera que esta función se encuentra estrictamente circunscrita a "la cumplida ejecución de las leyes", es decir, se encuentra limitada por el principio de reserva legal ${ }^{16}$, por lo que la discrecionalidad en la reglamentación estará restringida por los

administrativo, 13. ${ }^{\circ}$ ed., Bogotá: Legis, 2008 pp. 31 y 32. En igual sentido, HUMBERTO SIERRA PORTO, Concepto y tipos de ley en la Constitución Colombiana, Bogotá: Universidad Externado de Colombia, 1998, p. 320, quien expresa que los decretos ley son "un mecanismo que, en tanto descarga al Congreso de realizar regulaciones de carácter predominantemente técnico, lo potencia, al permitir concentrar su actividad en la discusión, control y regulación de materias de gran relevancia política".

15 No debe confundirse "poder" con "potestad". Aquel es lo genérico, esta lo especifico. El "poder" es atributo del Estado -latu sensu-, en tanto que la "potestad", en lo que respecta a su ejercicio, puede ser prerrogativa inherente a una función, verbigracia de la función correspondiente a la Administración pública. Las "potestades" constituyen un reflejo cualificado del "poder" general del estado, pero no pueden confundirse con este "poder". Miguel Marienhoff, Tratado de derecho administrativo, t. I, 5. ${ }^{\text {a }}$ ed., Buenos Aires: Abeledo Perrot, p. 624. En el mismo sentido ver a LiBARDo RodríGuez R., Derecho administrativo. General y colombiano, 9. ${ }^{\circ}$ ed., Bogotá: Temis, 1996. p. 62, "la ejecución de ley implica la expedición tanto de normas generales como individuales para su aplicación concreta. Entonces, cuando el presidente dicta normas generales con base en la ley para procurar su aplicación, estar ejerciendo la potestad reglamentaria, pero esta función se encuentra todavía dentro de la ejecución de las leyes".

16 "[L]a actividad administrativa debe ser eficaz en la realización del interés público, pero esta eficiencia o conveniencia u oportunidad es en algunos casos contemplada por el legislador o por los reglamentos y en otros es dejada a la apreciación del órgano que dicta el acto, en ello estriba la diferencia de las facultades regladas y discrecionales". Agustín Gordillo, Tratado de derecho administrativo, 10. ${ }^{a}$ ed., Buenos Aires: FDA, 2009, pp. XII-1. Por ello, "Tiene para el poder ejecutivo un efecto directamente limitador de su ámbito competencial, ya que las materias alcanzadas por la reserva, que no hayan sido objeto de previa regulación legal, no pueden ser reguladas por la administración. En tiempos, como los actuales, en que las situaciones y las exigencias varían rápidamente y en que la administración es juzgada políticamente por su capacidad de reacción rápida, tal exigencia no es, desde luego, una obviedad. El carácter político de la doctrina de la reserva de ley ha sido admitido siempre a lo largo de la evolución histórica". José Araújo JuÁreZ, Derecho administrativo, Parte general, Caracas: Ed. Paredes, 2008, p. 98. En consecuencia, "[1]a doctrina más reciente señala que si el principio del buon andamiento se identifica con la eficacia y la eficiencia de la administración pública, a la hora de constatar su vulneración o no antes de revisar "singulares actos" debe observarse una actividad administrativa en conjunto. Esta, sin duda, constituye una de las características principales del principio del buon andamento de la Administración pública en la actualidad, desde la perspectiva de su carácter vinculante: un principio que orienta la organización y la función administrativa y, desde esta última, se predica, no de acciones precisas de las administraciones públicas, sino de las actividades que suponen acciones, decisiones, organización, manejo de recursos, etc.". Cfr. Alberto Montaña PlatA, "El principio de buen funcionamiento de la administración pública y su carácter vinculante en la revisión judicial de actividades administrativas", en La constitucionalización del derecho administrativo: El derecho administrativo para la paz", Bogotá: Universidad Externado de Colombia, 2016, p. 363. 
parámetros que consigne el legislador ${ }^{17}$. Es por ello que la jurisprudencia de la Corte Constitucional se ha expresado que "La potestad reglamentaria, o el poder reglamentario, es un derecho propio constitucionalmente otorgado al Presidente de la República, como autoridad administrativa, para dictar las normas de carácter general que son necesarias para la correcta ejecución de la ley $[\ldots .$.$] pero su ejercicio se amplía o restringe en la medida en que el Con-$ greso utilice en mayor o menor grado sus poderes jurídicos" ${ }^{\prime \prime}$, lo que evidencia que dicha atribución no es absoluta y en consecuencia no puede alterar o modificar el espíritu de la ley o proceder a reglamentar materias que no están precedidas de una, en virtud de la distribución de competencias y el desarrollo del principio de coordinación. No obstante, situación diferente será aquella en la cual, a pesar de existir una ley, los parámetros se tornen tan amplios y abstractos que se vuelva confusa la materia a regular ${ }^{19}$.

Ahora bien, todo lo anterior adquiere plena relevancia en el caso concreto del marco de acción de la Agencia Nacional de Contratación de cara a sus funciones plenamente identificadas, pues a pesar de la clara especificación de sus competencias en su norma de creación, la cual tiene rango de ley, a través del reglamento expedido para el Estatuto General de Contratación de la Administración Pública se han atribuido funciones específicas a este organismo, lo que ha dado pie para que dicha entidad considere, y de hecho así lo ha manifestado directamente ${ }^{20}$, que los instrumentos que estructura y difunde en cumplimiento de lo expresamente establecido en su norma de creación tenga

17 "El ejercicio de esta potestad por el gobierno se amplía o restringe en la medida en que el Congreso haya utilizado sus poderes jurídicos. El grado de la reglamentación lo señala tácitamente y en cada caso el propio cuerpo legislativo. Tanta será la materia reglamentable por el ejecutivo, cuanta determine la necesidad de realizar el estatuto expedido por las cámaras". José LuIS BenAVIDES, "Potestad reglamentaria. Relación de dependencia frente a la ley reglamentada", en Los grandes fallos de la jurisprudencia administrativa colombiana, Bogotá: Universidad Externado de Colombia, 2013. p. 98. "Admitido que lo prohibido como incapacidad al órgano o ente administrativo puede ser tácito o implícito, no existe tampoco argumento político alguno que pueda hacerse en contra, sobre la base de que un ilimitado orbe de competencia llevaría al absolutismo de Estado a través de una administración cesarista". JuAN F. LiNARES, "Competencia administrativa y prohibiciones implícitas", RADA, N. ${ }^{\circ} 8$, Buenos Aires, 1975 , pp. 15 y ss.

18 Corte Constitucional, Sentencia C- 028/1997; y en igual sentido, la doctrina ha expresado que "La esencia de la discrecionalidad está dada por una libertad de determinación o habilitación que el ordenamiento jurídico confiere, empero al mismo tiempo dicha discrecionalidad se encuentra restringida por este". Cfr. Julio R. ComadiRA, "La actividad discrecional de la administración pública. Justa medida de control judicial", El Derecho, Buenos Aires, 29 de marzo de 2000.

19 Cfr. Corte Constitucional, Sentencias C-265/2009 y C-474/ 2007

20 "Adicionalmente, si el manual o guía fue adoptado por Colombia Compra Eficiente mediante Circular Externa y esta a su vez fue divulgada, es de obligatorio complimiento". Colombia, Agencia Nacional de Contratación, Colombia Compra Eficiente, respuesta a consulta de 26 de agosto de 2016, Radicación n. ${ }^{\circ} 416140004395$. 
carácter vinculante en la medida en que tengan la naturaleza intrínseca de ser actos administrativos ${ }^{21}$. Por ello, vale la pena analizar las implicaciones de que la jurisprudencia considere que las funciones y facultades puedan ser producto de la potestad reglamentaria y no de la función legislativa, especialmente bajo un modelo de descentralización territorial como el que nos cobija por mandato de la Constitución Política.

En lo que se refiere al régimen jurídico de la Agencia Nacional de Contratación Estatal, como ya se mencionó, el Decreto Ley 4170 de 2011 establece unas funciones concretas que caracterizan su papel de unidad administrativa especial, frente a la cual, para efectos de analizar la posición de la jurisprudencia, se destaca la de "Diseñar, organizar y celebrar los acuerdos marco de precios y demás mecanismos de agregación de demanda de que trata el artículo $2 .^{\circ}$ de la Ley 1150 de 2007, de acuerdo con los procedimientos que se establezcan para el efecto", con base en lo cual el Gobierno Nacional, en ejercicio de la potestad reglamentaria, estableció en el artículo 2.2.1.2.1.2.9 del Decreto 1082 de 2015 (compilando el artículo 46 del Decreto 1510 de 2013), relativo a la utilización del acuerdo marco de precios, que "Si el Catálogo para Acuerdos Marco de Precios contiene el bien o servicio requerido, la Entidad Estatal de que trata el inciso 1 del artículo 2.2.1.2.1.2.7 del presente decreto está obligada a suscribir el Acuerdo Marco de Precios, en la forma que Colombia Compra Eficiente disponga, y luego puede colocar la orden de compra correspondiente en los términos establecidos en el Acuerdo Marco de Precios", demandándose en acción de nulidad, y para lo que aquí nos interesa, el componente de la norma relativo a que el las entidades estatales deberán suscribir los acuerdos marco de precios en la forma en que la Agencia Nacional de Contratación establezca.

La norma en comento, previo a hacer cualquier análisis sobre la misma, debe ser analizada en contexto junto con el artículo 2.2.1.2.5.2. del mismo Decreto 1082 de 2015, que dispuso que Colombia Compra Eficiente tiene la función de expedir manuales para el uso de los acuerdos marco de precios, sin perjuicio de las funciones que el Decreto Ley 4170 de 2011 le asigna a esta entidad; y con base en ello, actualmente existen la Guía para entender los Acuerdos Marco de Precios (Versión G-EAmp-01 de 21 de febrero de 2013) y el Manual para la Operación Secundaria de los Instrumentos de Agregación de

21 "Se considera acto administrativo solo a las declaraciones administrativas (unilaterales y bilaterales, individuales y generales) con efectos jurídicos directos. Así, el acto administrativo comprende de los reglamentos y de los contratos. Vale decir que las formas jurídicas administrativas son acto (declaraciones con efectos directos), hecho (actuaciones materiales) y simple acto de la Administración (declaraciones con efectos directos)". ROBERTO Dromi, El acto administrativo, 3. ${ }^{a}$ ed., Buenos Aires: Ediciones Ciudad Argentina, 2000, p. 14. 
Demanda, actualizado el pasado 20 de abril de 2017 ${ }^{[22]}$. Dichos documentos, y en especial el último referido, se conciben como instrumentos de gerencia que permiten mayor trasparencia y eficacia en las relaciones de contratación, sobre los cuales existe discusión sobre su carácter vinculante, toda vez que las facultades que le son conferidas a dicha entidad para la expedición de dichos documentos no son producto de lo establecido en normas de rango legal, y ni siquiera en las funciones consagradas en su norma de creación, sino que, precisamente derivan de una disposición de orden reglamentario, tesis bajo la cual podría considerarse que dichas disposiciones son contrarias al principio de reserva lega ${ }^{23}$, frente a lo cual algún sector de la doctrina considera que "al carecer tales normas (rectius los lineamientos, guías y manuales de CCE de fundamento legal expreso que les reconozca carácter vinculante y ser expedidas en ejercicio de una función orientadora, pedagógica, instructiva y meramente promocional de las mejores prácticas jurídicas en este campo, no cabe duda que se trata de actos jurídicos desprovistos de tales efecto" ${ }^{\prime 2}$, a lo que se opone otro sector, según el cual "si la circular que emita la Agencia como manifestación de la voluntad tiene, en el marco de las normas que regulan la contratación estatal, la potencialidad de producir efectos jurídicos, se tendrá como un verdadero acto administrativo, revestido de presunción de legalidad

22 Dicha actualización de produce como consecuencia de la medida cautelar de suspensión provisional proferida por el Consejo de Estado, Sección Tercera, Subsección A, mediante auto 56.307 del 29 de marzo de 2017, respecto de la afirmación contenida en el mismo de que en caso de conflicto entre las modalidades de selección abreviada por la causal de bienes y servicios de características técnicas uniformes, y específicamente ante la existencia de un acuerdo marco de precios vigente, y la de mínima cuantía, primaba el acuerdo marco de precios. Al respecto, la Corporación sostuvo en la providencia que "cuando el monto de la contratación sea equivalente a la mínima cuantía de la entidad estatal, pero, concomitante a ello, esta última (la entidad) advierta que también aplica alguna modalidad de selección específica (dadas las condiciones especiales del objeto), ella debe acudir el procedimiento establecido para la mínima cuantía", razón por la cual Colombia Compra Eficiente debió ajustar el documento a lo dicho en la misma.

23 "[E]n cuanto a su versión inicial comporta un doble contenido i) las materias reservadas a la ley deben ser reguladas absolutamente por la ley formal, de tal modo que no puede quedar ningún requisito para la iniciativa administrativa que no esté preconfigurado $;$ y ii) la ley es exclusivamente la ley formal, como lógica consecuencia de que solo a través de las leyes aprobadas por el parlamento se manifiesta la voluntad general. Significa que la regulación de determinadas materias - del máximo relieve para la convivencia- necesariamente debe provenir de normas que sean leyes formales. así, en su sentido originario supone que la constitución reserva exclusivamente a le ley formal la completa regulación de una materia, por lo que, en consecuencia, coinciden plenamente los principios de reserva legal y de legalidad en sentido formal". José Araújo JuárEZ, Derecho administrativo, Parte general, Caracas: Ed. Paredes, 2008, p. 140.

24 Héctor Santaella Quintero, "El doble nivel, vinculante y no vinculante, de la reglamentación en la contratación pública en Colombia", en Contratos Públicos: problemas, perspectivas y prospectivas, XVIII Jornadas internacionales de Derecho Administrativo, Bogotá: Universidad Externado de Colombia, 2017, p. 814. 
y de obligatorio cumplimiento para sus destinatarios" 25 , lo cual se haría extensivo a los manuales, guías y lineamientos que expida la Agencia, cuando ellos se encuentren plasmados en una, o sean presentados por una, circular externa de esta entidad.

Ahora bien, en este contexto ya especificado, la posición del Consejo de Estado para avalar la legalidad de la atribución hecha a Colombia Compra Eficiente de establecer los términos en que se deberá suscribir los acuerdos marco de precios vigentes por las entidades estatales que están obligadas a ello ${ }^{26}$, es que el Decreto Ley 7170 de 2011, norma de creación de la Agencia Nacional de Contratación, estableció como función de la misma diseñar, organizar y celebrar los acuerdo marco de precios de acuerdo con los procedimientos que se establezcan para el efecto, y como consecuencia de ello la norma reglamentaria se ha limitado a concretar la competencia en dicho marco, lo que se traduce en el "establecimiento de las condiciones jurídicas, logísticas y operacionales que demanda esa figura para su debida ejecución y aplicación por cuenta de las Entidades obligadas (o que facultativamente han adherido) al Acuerdo Marco de Precios y que deben ejecutar la llamada operación secundaria que, como se dijo, es la particularización de negocios jurídicos puntuales en los que se entienden trasvasados la totalidad del clausulado convenido en el contrato o acuerdo marco", de modo que "no es expresión de un poder reglamentario similar o propio al atribuido por la Constitución al Presidente de la República en el artículo 189.11 superior, pues no se trata de despliegue normativo para asegurar la cumplida ejecución de la Ley sino que lo es para garantizar la recta ejecución del Acuerdo Marco de Precios en tanto negocio jurídico" ${ }^{127}$.

En este orden de ideas, se observa que la jurisprudencia hace una clara diferenciación entre la atribución de una competencia por vía de reglamento y la concreción de una competencia ya establecida por el legislador mediante la

25 Cfr. Felipe De Vivero, "Las funciones de consulta y expedición de circulares asignadas a la Agencia Nacional de Contratación en el marco de la entrada en vigencia del nuevo Código de Procedimiento Administrativo y de lo Contencioso Administrativo", en Tratado general de los contratos públicos, Buenos Aires: La Ley, 2013, p. 1198.

26 Debe ponerse de presente que la obligatoriedad de uso de acuerdos marco de que trata el artículo 2.2.1.2.1.2.7 del Decreto 1082 de 2015 actualmente se encuentra demandada por contravención directa con lo dispuesto en el parágrafo $5 .^{\circ}$ del artículo $2 .^{\circ}$ de la Ley 1150 de 2007, estando a la fecha pendiente la decisión sobre la medida cautelar de suspensión provisional. El argumento consiste en violación de los límites de la potestad reglamentaria, pues la ley ordenó al Gobierno establecer "las condiciones bajo las cuales el uso de acuerdos marco de precios se hará obligatorio para las entidades de la Rama Ejecutiva del Poder Público en el Orden Nacional, sometidas al Estatuto General de Contratación de la Administración Pública", mientras que el reglamento establece de manera absoluta que estas entidades "están obligadas a adquirir Bienes y Servicios de Características Técnicas Uniformes y de Común Utilización a través de los Acuerdos Marco de Precios Vigentes".

27 Consejo de Estado, Sala de lo Contencioso Administrativo, Subsección A, Sentencia del 16 de agosto de 2017, Exp. 56.166. 
especificación de una atribución concreta ${ }_{i}$ y en el caso concreto de la norma impugnada, en efecto se observa que si es la Agencia Nacional de Contratación la encargada de diseñar, organizar y celebrar los acuerdos marco de precios, un componente propio de la organización de los mismos es el relativo a cómo las entidades estatales se vincularán a estos, para efectos de que Colombia Compra Eficiente pueda hacer el control sobre su funcionamiento de cara tanto a los proveedores (contratistas) como a las entidades usuarias, especialmente si se tiene en cuenta que cualquier organismo del Estado, sea parte o no de la rama ejecutiva o esté o no en el orden nacional de la misma, puede acudir a la utilización de esta herramienta ${ }^{28}$, lo que implica que las entidades territoriales en los niveles central y descentralizado por servicios, así como las ramas legislativa y judicial y los organismos autónomos, serán los rectores de sus propios acuerdos marco de precios y establecerán las reglas para su diseño, organización y celebración.

Pero, precisamente en el marco de esta diferenciación, es importante fijar una posición concreta sobre los alcances de esa "facultad regulatoria no vinculante" de la Agencia Nacional de Contratación, pues, como bien lo ha expresado la jurisprudencia en comento, la competencia debe derivar de la ley, y solo en dicho contexto podrán validarse disposiciones reglamentarias que otorguen carácter obligatorio a los instrumentos que esta entidad cree y divulgue; de manera que, a partir de esta premisa, debe decirse, indefectiblemente, que no todo manual, guía, lineamiento o circular externa que expida Colombia Compra Eficiente será de obligatorio cumplimiento, sino solamente aquellos que se estructuren en cumplimiento de una función expresamente atribuida por una norma de rango legal que concretamente manifieste una atribución de creación y desarrollo de instrumentos específicos. Así, solo con base en una norma legal el reglamento podrá determinar el alcance de dicha función y la entidad podrá generar las herramientas administrativas necesarias para el efecto $_{;}$y esto es importante porque, a la luz de la normatividad vigente, solamente la función aquí estudiada relacionada con los acuerdos marco de precios consagra el tipo de atribuciones que permiten el desarrollo reglamentario que avala jurídicamente la generación de documentos vinculantes por la Agencia Nacional de Contratación.

28 Así lo dispone el parágrafo 5. ${ }^{\circ}$ del artículo 2..$^{\circ}$ de la Ley 1150 de 2007 ya referido, al consagrar que "En el caso de los Organismos Autónomos y de las Ramas Legislativa y Judicial, así como las Entidades Territoriales, las mismas podrán diseñar, organizar y celebrar acuerdos marco de precios propios, sin perjuicio de que puedan adherirse a los acuerdos marco a que se refiere el inciso anterior". 


\section{3. ¿Y CÓMO ENTENDER EL RECONOCIMIENTO JURISPRUDENCIAL DE LAS COMPETENCIAS A LA AGENCIA NACIONAL DE CONTRATACIÓN EN EL MARCO DE UN MODELO DE ESTADO DESCENTRALIZADO TERRITORIALMENTE?}

Así las cosas, se hace evidente que, con la posición de la jurisprudencia en los términos aquí explicados, no se contradice el concepto mismo de la descentralización territorial, la cual, al tratarse del traslado de competencias a personas jurídicas distintas de aquella del Estado en su núcleo central ${ }^{29}$, de suyo implica el ejercicio de autonomía que se encuentra limitada únicamente por la ley-como lo ordena el artículo 287 constitucional ${ }^{30}$ - Es esencial hacer énfasis en esta premisa, toda vez que un entendimiento erróneo del contenido

29 "En derecho administrativo, la descentralización se presenta entre distintas personas jurídicas de derecho público. [...] La descentralización se presenta -jurídicamente-siempre y cuando se garantice y se reconozca a cada entidad descentralizada su existencia como una persona jurídica. Por lo tanto, no hay entidad descentralizada territorial o por servicios que no sea persona jurídica autónoma, con su propia personalidad jurídica". PEDRO Alfonso Hernández M., Descentralización, desconcentración y delegación en Colombia, Bogotá: Legis, 2005, p. 98.

30 "El principio de autonomía se desarrolla cuando al definir los caracteres de las entidades territoriales, no sólo les atribuye competencias propias, que son de la esencia de su autonomía, sino que afirma derechos y consagra poderes exigibles y oponibles a las autoridades de los niveles superiores, lo que indudablemente supone un cambio cualitativo en la concepción de estos entes". Corte Constitucional, Sentencia C-126 de 1993. También ha dicho la jurisprudencia constitucional en Sentencia C-520 de 1994 que "La autonomía de que gozan las entidades territoriales debe desarrollarse dentro de los marcos señalados en la Carta Política y con plena observancia de las condiciones que establezca la ley, como corresponde a un Estado social de derecho constituido en forma de República unitaria. Es decir, no se trata de una autonomía en términos absolutos, sino por el contrario, de carácter relativo. De todo lo anterior se deduce que si bien es cierto que la Constitución de 1991 estructuró la autonomía de las entidades territoriales dentro del modelo moderno de la descentralización, en ningún momento se alejó del concepto de unidad que armoniza los intereses nacionales con los de las entidades territoriales, que se encuentran limitadas por las regulaciones de orden constitucional y legal en lo que respecta a la distribución y manejo de los recursos que deben tener en cuenta aquellas pautas generales encaminadas a satisfacer las verdaderas necesidades de las regiones, departamentos, distritos, municipios y territorios indígenas", y en su salvamento de voto que "Mientras la descentralización es genérica, corresponde a una técnica de organización por la cual las instancias periféricas gozan de un mayor o menor grado de libertad en la toma de sus decisiones, con miras a la eficiencia en el manejo de los asuntos públicos, el rasgo de la autonomía implica el reconocimiento constitucional de un conjunto de verdaderos derechos en cabeza de las entidades territoriales, en cuya virtud afirman su independencia del centro en lo que atañe, entre otros aspectos, al establecimiento de normas propias, la escogencia de sus autoridades, la gestión de sus intereses y la administración de sus recursos". En igual sentido, ver a Pedro Alfonso Hernández M., cit., p. 79: "En síntesis, el legislador cuenta con las restricciones que le establece la Constitución para fijar los límites a la autonomía de las 
de esta providencia, y con ello de la postura de la máxima instancia del Contencioso Administrativo, podría dar al traste con este componente básico del modelo de Estado en Colombia, pues, de generalizarse la idea de facultades regulatorias de Colombia Compra Eficiente, se desvirtuaría sin duda alguna la descentralización territorial, y con ello la función expresa conferida a la Agencia Nacional de Contratación de "Brindar apoyo a las entidades territoriales para la adecuada aplicación de las políticas, instrumentos y herramientas en materia de compras y contratación pública", la cual, evidentemente, reconoce la autonomía del nivel territorial -y de paso, la de las demás ramas del poder y los organismos autónomos- en concordancia con la postura de la Corte Constitucional de que dicha entidad "No se trata de un órgano con competencias reglamentarias, sino doctrinales y de fijación de políticas públicas" ${ }^{131}$.

Es así como la competencia de la Agencia Nacional de Contratación, de cara a la descentralización territorial, se compagina únicamente para efectos de los relativo a los instrumentos creados por esta entidad para un aspecto específicamente delimitado, y solamente será aplicable a este nivel en la medida en que una entidad territorial decida, luego de haber efectuado el análisis correspondiente en la fase de planeación del proceso de contratación, utilizar la herramienta de los acuerdos marco de precios, pues deberá en este caso acogerse a los parámetros establecidos por dicha entidad al ser aquella la encargada del diseño, organización y celebración de los mismos por mandato legal $_{i}$ en consecuencia, cualquier otro documento expedido por Colombia Compra Eficiente, que de por sí no tiene carácter vinculante en los términos ya expuestos, debe analizarse a la luz de las funciones de orientación dentro de la política pública de contratación estatal (una vez la misma se encuentre debidamente aprobada e incorporada en instrumentos jurídicos vinculantes) y acompañamiento al nivel territorial para su adecuada implementación, con miras a generar una visión común del sistema de compras públicas en todos los órdenes y niveles del Estado.

Cualquier interpretación en otro sentido desvirtuaría la esencia de nuestro modelo constitucional de Estado, generando un retroceso hacia el centralismo y desconociendo que la misma jurisprudencia constitucional expresamente ha reconocido que

La autonomía es un elemento sustancial de la organización del Estado colombiano y tiene su especificidad frente a la descentralización. Por ello la autonomía de las entidades territoriales se distingue de la descentralización territorial. Mientras que la descentralización se reitere al contenido material, a las competencias y recursos asignados por la Constitución y la ley a los entes territoriales, la autonomía consiste

entidades territoriales. El legislador no está facultado para establecer discrecionalmente las fronteras a la autonomía territorial". 
en el margen o capacidad de gestión que el constituyente y el legislador garantizan a las entidades territoriales para que planeen, programen, dirijan, organicen, ejecuten, coordinen y controlen sus actividades, en aras del cumplimiento de las funciones y fines del Estado. Además, la autonomía es una consecuencia sine qua non de la descentralización, aunque no es exclusiva de esta. No es previsible un régimen de descentralización como forma de organización política de un Estado, en donde no haya autonomía de los entes territoriales.

En conclusión, la reivindicación de competencias de Colombia Compra Eficiente por el Consejo de Estado no se constituye en nuevo alcance de la potestad reglamentaria ni en interpretación extensiva de la ley por la jurisprudencia, sino el reconocimiento expreso de que, en un caso concreto y a partir del estudio de una competencia específicamente atribuida a la Agencia Nacional de Contratación en una norma de rango legal, cumpliéndose con el presupuesto exigido para el efecto, esta entidad expedirá documentos que se convierten en obligatorios y vinculantes dentro del marco específico de la función asignada, no pudiendo extenderse dicho análisis a la totalidad de los manuales, guías, circulares externas, lineamientos y documentos tipo que la misma ha expedido. Sin embargo, es importante poner de presente que con ello no se quieren desnaturalizar las funciones de Colombia Compra Eficiente y que se encuentran expresas en su norma de creación en concordancia con su naturaleza jurídica, pues este tipo de instrumentos se constituyen en herramientas de gestión que suponen, en la gran mayoría de los casos, criterios técnicos de optimización en las relaciones contractuales del Estado en el marco del denominado Sistema de Compra Pública, que si, luego de un análisis de los mismos por parte de cada una de las entidades estatales, se considera son idóneos, oportunos y acertados, son un norte que no se debería desconocer, entrando así en el campo del derecho blando ${ }^{32}$.

En este orden de ideas, no es correcto afirmar que toda expresión de la administración proferida de forma unilateral y publicada es un acto administrativo, pues se requiere del presupuesto de la competencia con el lleno de los requisitos que ella exige para su configuración, ya que de lo contrario se afectaría el principio de legalidad, "base constitucional del derecho administrativo"33.

33 "El postulado de la legalidad representa base constitucional del Derecho Administrativo y, como tal, es elemento básico del Estado de derecho, porque es su manifestación primaria y esencial. En igual forma, constituye presupuesto de los otros elementos que lo integración lo cual, respecto de los contratos del Estado, siendo estos temática del Derecho Administrativo, actividad típicamente administrativa, su presencia se encuentra más que justificada. Es nada más y nada menos que un principio garantista, en cuanto contribuye a la seguridad jurídica, en el régimen político que sea". Juan Carlos Expósito Vélez, La configuración del contrato de la administración pública en derecho colombiano y español, Bogotá: Universidad Externado, 2003, p. 398. 


\section{BIBLIOGRAFÍA}

Araújo JuÁrez, José. Derecho administrativo, Parte general, Caracas: Ed. Paredes, 2008.

AriÑo Ortiz, GasPar. Lecciones de administración (y políticas públicas), Madrid: Iustel, 2011.

BenAVIDES, José LuIs. El contrato estatal, entre el derecho público y el derecho privado, 2. a ed., Bogotá: Universidad Externado de Colombia, 2004.

BenAvides, José Luís. "Potestad reglamentaria. Relación de dependencia frente a la ley reglamentada", en Los grandes fallos de la jurisprudencia administrativa colombiana, Bogotá: Universidad Externado de Colombia, 2013.

Colombia, Agencia Nacional de Contratación (Colombia Compra Eficiente). Respuesta a consulta de 26 de agosto de 2016, Radicación \#416140004395.

Colombia, Departamento Nacional de Planeación. Bases del Plan Nacional de Desarrollo 2010-2014.

COMAdiRA, Julıo R. La actividad discrecional de la administración pública. Justa medida de control judicial, Buenos Aires: El Derecho, 29 de marzo de 2000.

Dromi, Roberto. Derecho administrativo, 3. a ed., Buenos Aires: Ediciones Ciudad Argentina, 2000.

EXPÓSITO VÉLEZ, JuAN CARLÓs. La configuración del contrato de la administración pública en derecho colombiano y español, Bogotá: Universidad Externado de Colombia, 2013.

Gordillo, Agustín. Tratado de derecho administrativo, 10. a ed., Buenos Aires: FDA, 2009.

Hernández M., Pedro Alfonso. Descentralización, desconcentración y delegación en Colombia, Bogotá: Legis, 2005.

IVANEGa, Miriam. Instituciones de derecho administrativo, 2. ${ }^{a}$ ed., Bogotá: Universidad Externado de Colombia, 2013.

LinARES, JuAn F. "Competencia administrativa y prohibiciones implícitas", RADA, N. 8, Buenos Aires, 1975.

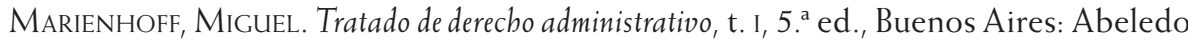
Perrot, 2003.

Montaña Plata, AlBerto. "El principio de buen funcionamiento de la administración pública y su carácter vinculante en la revisión judicial de actividades administrativas", en La constitucionalización del derecho administrativo: El derecho administrativo para la paz, Bogotá: Universidad Externado de Colombia, 2016. 
Perdomo Vidal, Jaime. Derecho administrativo, 13. ed., Bogotá: Legis, 2008.

RodríGuez R., Libardo. Derecho administrativo, general y colombiano, 9. ${ }^{a}$ ed., Bogotá: Temis, 1996.

Santaella Quintero, Héctor. "El doble nivel, vinculante y no vinculante, de la reglamentación en la contratación pública en Colombia", en Contratos públicos: problemas, perspectivas y prospectivas, XVIII Jornadas internacionales de Derecho Administrativo, Bogotá: Universidad Externado de Colombia, 2017.

Sierra Porto, Humberto. Concepto y tipos de ley en la constitución colombiana, Bogotá: Universidad Externado de Colombia, 1998.

Villoria Mendieta, Manuel. Ética pública y buen gobierno. Regenerando la democracia y luchando contra la corrupción desde el servicio público, Madrid: Instituto Nacional de Administración Pública, 2015.

\section{NORMATIVIDAD}

Constitución Política de Colombia.

Ley 489 de 1998.

Ley 1150 de 2007.

Decreto Ley 4170 de 2011.

Decreto 1082 de 2015.

JURISPRUDENCIA

Corte Constitucional, Sentencia C-126 de 1993.

Corte Constitucional, Sentencia C- 028 de 1997.

Corte Constitucional, Sentencia C-474 de 2007.

Corte Constitucional, Sentencia C-520 de 1994.

Corte Constitucional, Sentencia C-265 de 2009.

Corte Constitucional, Sentencia C-004 de 2017.

Consejo de Estado, Sala de lo Contencioso Administrativo, Sección Tercera, Auto del 19 de febrero de 1998, Exp. 14.092. 
Consejo de Estado, Sala de lo Contencioso Administrativo, Sección Tercera, Sentencia del 3 de diciembre de 2007, Exp. 24.715.

Consejo de Estado, Sala de lo Contencioso Administrativo, Subsección A, Sentencia del 16 de agosto de 2017, Exp. 56.166.

Consejo de Estado, Sala de Consulta y Servicio Civil, Concepto del 16 de abril de 2015, Rad. 2223. 